\title{
Reformas municipal y agraria, expansión urbano-regional y gestión del suelo urbano en México
}

\author{
Guillermo Olivera Lozano*
}

\begin{abstract}
This paper analyses the legal and institutional framework of the urban planning process in Mexico and its deficiencies are explained. In particular, we revise and compare the 27 th and 115 th constitutional articles, which dictate and affect the role of the municipality in the urban development process. First, we briefly characterise both articles at different stages and then develop a more detailed account of their most recent changes. The results show that in spite of the breakthroughs achieved, the municipalities are still facing obstacles to performance in their urban management tasks. One of the most important pitfalls is the existing opposition in some aspects of the above mentioned articles. On top of this, we also have the ever-present centralism and the verticality in the federal public policies in the urban sector, in which the municipality still subordinates the other two levels of government. All this is preceded by a characterisation of the gap that the country has developed between urban and economical growth.
\end{abstract}

Keywords: municipality, urban planning, urban regional problems, 27th and 115 th constitutional articles.

\section{Resumen}

Este trabajo analiza el marco jurídico e institucional del proceso de planeación urbana en México y sus deficientes resultados. Se revisan y comparan en particular los artículos 27 y 115 constitucionales, que norman e inciden en la actuación del municipio sobre los procesos de desarrollo urbano. Primero se hace una breve caracterización de cada uno en distintas etapas y después se desarrollan en detalle sus reformas. Los resultados muestran que, pese a los avances logrados, los municipios siguen enfrentando obstáculos para desempeñar sus tareas de gestión urbana; uno de los escollos más importantes es la contraposición en algunos aspectos de dichos artículos. A ello se suman el centralismo y la verticalidad de las políticas públicas federales del sector urbano, donde el municipio sigue subordinado a los otros dos niveles de gobierno. A todo ello lo antecede una caracterización sobre el desfase que ha experimentado el desarrollo del país en cuanto a crecimiento urbano y económico.

Palabras clave: municipio, planificación urbana, problemas urbanoregionales, artículos 27 y 115 constitucionales.

* Centro Regional de Investigaciones Multidisciplinarias, unam. Correo-e: gol@servidor.unam.mx. 


\section{Introducción}

La planeación y gestión del desarrollo urbano en México, como se sabe, ha tenido magros resultados desde su institucionalización a fines de los años setenta, cuando vivió un auge efímero, hasta la actualidad, en que ha estado relegada por la falta de perspectivas de lograr eficacia mediante su aplicación. A diferencia de los años setenta y ochenta, sin embargo, cuando las condiciones políticas e institucionales eran totalmente adversas para lograr una adecuada gestión del suelo urbano, durante los años noventa del siglo xx ocurrieron cambios que, en el largo plazo, permitirían dar algunos pasos en la dirección opuesta. En particular, en el sentido de incidir en un mejor ordenamiento de la expansión urbana y en un mayor control sobre el crecimiento 'ilegal' de los asentamientos populares.

Entre los cambios señalados destaca la reforma municipal de 1999 como parte de la reforma del Estado y de la democratización de la vida política en el país, al igual que la reforma de 1992 al Artículo 27 constitucional como parte de las reformas económicas orientadas hacia la apertura comercial e inserción internacional. Estas dos reformas modificaron radicalmente el marco jurídico en que se desenvolvieron la política urbana en general y la política de suelo urbano en particular durante los años setenta y ochenta, y constituyen el punto de partida para el desarrollo de nuevas políticas de suelo en las ciudades mexicanas. A partir de ello, se encuentra también en proceso de transformación el andamiaje institucional desde donde se desarrollan y organizan las políticas de suelo.

En relación con la reforma municipal de 1999 mediante las modificaciones al Artículo 115 constitucional, el cambio fue que, al fin, se cumplió una demanda social y política vigente durante la mayor parte del siglo xx: reconocer a los municipios su carácter de gobierno y ya no sólo de entidad administrativa. Con esto, y al dejar abierta la posibilidad de que cada entidad federativa adaptara el contenido de la reforma federal a su propia realidad, se dio un paso más hacia una descentralización político-administrativa que, dependiendo de que se superen limitaciones económicas, de cuadros profesionales y de otro tipo que tienen en su mayoría los municipios, deberá reflejarse forzosamente en una mejor gestión del suelo urbano. Como podrá apreciarse a lo largo del trabajo, la reforma representó avances en algunos aspectos de la vida municipal, pero mantuvo trabas en otros, entre las 
que destaca el punto de las relaciones intergubernamentales entre municipio, estados y gobierno federal. De la forma en que en cada espacio urbano se combinen las ventajas y desventajas de la reforma, y de cómo se haya adaptado en su propia legislación, dependerán en gran medida los resultados de la gestión del suelo.

En lo que respecta a la reforma al Artículo 27 constitucional, el cambio consistió en permitir, por primera vez en la historia de los ejidos, la renta y venta de la tierra y posibilitar la incorporación de los ejidos al desarrollo urbano ordenado, con la participación de las autoridades municipales urbanas en colaboración con las autoridades agrarias.

El objetivo del trabajo es, por una parte, describir y analizar los cambios en el marco jurídico que regula la actuación de los gobiernos municipales en sus tareas de gestión del suelo urbano, en específico los artículos 27 y 115 constitucionales, con énfasis tanto en las ventajas que representa como en los obstáculos que todavía impone para el trabajo de dichos niveles de gobierno. Por otra parte, interesa también exponer las características y dimensiones del proceso que están enfrentando los municipios en materia de suelo urbano: la urbanización en sus escalas local y regional.

Dado que en los resultados recientes de la gestión del suelo urbano predomina el estancamiento sobre los avances, se asumen dos elementos de explicación. Primero, que existe un desfase entre el ritmo de crecimiento y expansión urbana de las ciudades en relación con la baja capacidad de crecimiento de la economía nacional. Cabría agregar que también hay un problema de falta de comprensión y conocimiento cabal de los procesos territoriales urbano-regionales que están ocurriendo en la actualidad en torno a las grandes metrópolis.

En segundo lugar, las reformas a los artículos 27 y 115 no han aportado todos los elementos necesarios para una mejor gestión del suelo urbano. Por una parte, porque el Artículo 27 aún mantiene candados a la conformación de un mercado de suelo urbano fluido. Por otra parte, aun cuando el Artículo 115 reconoce la capacidad de gobierno de los municipios, así como su diversidad, todavía se mantiene el carácter centralista de la planeación del suelo urbano.

La primera parte del documento aborda algunas dimensiones del proceso urbano en su fase actual en México. La segunda sección hace una breve referencia al origen histórico del municipio, con la finalidad de entender su función tradicional más orienta- 
da hacia la administración que como un nivel efectivo de gobierno; en este mismo sentido se exponen los problemas financieros y de recursos humanos -entre otros- que caracterizan a estas unidades político-administrativas y que han constituido una seria limitante para los objetivos de la planeación y gestión urbanas; naturalmente, se analizan las distintas reformas municipales, con énfasis en la de 1999.

El tercer apartado revisa lo concerniente al Artículo 27 y la contradicción que representa para la gestión del suelo urbano al contraponer el sector agrario con el sector urbano. Finalmente, la última parte discute la disociación entre el proceso de reforma municipal (que deposita o consolida en el municipio algunas facultades específicas que le permiten participar en la gestión de los problemas urbanos con mayor capacidad que antes), y el mantenimiento de la planeación urbana como un proceso centralizado donde el gobierno federal determina las normas y lineamientos generales que deben ejercer en cada entidad federativa las delegaciones representantes de las secretarías de Estado que tienen que ver con el sector de desarrollo urbano. Se mostrará que el centralismo y la verticalidad en la elaboración de las políticas públicas del sector urbano, por consiguiente, actúan en contra de algunos de los avances obtenidos por los municipios a raíz de la reforma al Artículo 115.

\section{El desfase entre los problemas urbanos, el crecimiento económico, la eficacia de las instituciones y la planeación con sus instrumentos}

En un sentido amplio, los problemas urbanos en México durante el siglo xx se convirtieron en tales porque el dinamismo de los procesos de expansión demográfica y territorial de la población no tuvo correspondencia con la capacidad de crecimiento de la economía ni con la comprensión cabal de los efectos de la urbanización (altos costos ambientales y socioeconómicos), ni con el aumento de la capacidad de las instancias públicas para hacerles frente. Así, históricamente fue conformándose un desfase entre todos estos aspectos. 


\subsection{Urbanización sin desarrollo por mayor crecimiento de la población}

Por una parte el desarrollo económico no es posible sin ciudades, ya que la urbanización es la traducción en el espacio de la distribución más eficaz de los recursos entre la ciudad y el campo; el resultado de esta mayor eficacia puede observarse en las ganancias de productividad que resultan a favor de la ciudad, y por lo tanto también en un producto interno bruto (PIB) por habitante más elevado. Sin embargo, a partir de cierto umbral en el nivel de urbanización de un país, que se ubica entre el 60\% y $70 \%$, las tasas de urbanización tienen cada vez menos significado como indicadores de progreso económico (Polèse, 1998: 115). Si a esto agregamos una situación de crisis o recesión económica prolongada como en el caso de México, la capacidad de sus instituciones públicas para hacer frente a las demandas de la población se ven disminuidas drásticamente.

Para corroborar lo anterior, son suficientes algunos datos y ejemplos. En 1980, a cuatro años de aprobada la primera Ley General de Asentamientos Humanos y a dos años de haberse publicado el primer Plan Nacional de Desarrollo Urbano, la población total del país era de 66.8 millones de habitantes, existían 227 ciudades $^{1}$ donde habitaban 37.4 millones, o $55.9 \%$ de la población total del país, y sólo tres ciudades rebasaban el millón. En el año 2000, la población total había alcanzado los $97.4 \mathrm{mi}-$ llones, el número de ciudades era de 364 y la población urbana de 63.2 millones o $66 \%$ de la población total; para entonces nueve ciudades habían alcanzado el millón de habitantes.

Así, en tan sólo 20 años se incorporaron 30.6 millones a la población total y 25.8 millones a las ciudades, en tanto que a estas mismas se le sumaron 137 nuevos centros de población. Las tasas de crecimiento promedio anual de la población, por decenios, fueron de la siguiente manera: en el caso de la población total, 3.2\% entre 1970 y 1980, 2.0\% entre 1980 y 1990, y $2.2 \%$ de 1990 al 2000; en el caso de la población urbana las tasas fueron de $3.7 \%, 3.1 \%$ y $2.2 \%$, respectivamente.

El crecimiento económico, mientras tanto, ha seguido una evolución contraria al crecimiento de la población, ya que de una tasa promedio de crecimiento del PIB total de $6.7 \%$ en los años setenta, se cayó hasta 1.2\% en los ochenta y 3.1\% durante

\footnotetext{
${ }^{1}$ Una ciudad es toda localidad con 15 mil o más habitantes.
} 
los noventa. El PIB per cápita, por su parte, pasó de una tasa de $3.1 \%$ en los años setenta a otra de $-0.3 \%$ en los ochenta y otra de $1 \%$ en los noventa.

Como resultado de lo anterior, los retos de las autoridades urbanas para cubrir las necesidades de infraestructura física y social de las ciudades en el país, así como para prever las necesidades de suelo para un crecimiento urbano ordenado, resultan formidables. En relación con esto último, por ejemplo, durante el último lustro del siglo xx se requirieron 150 mil hectáreas de suelo para el crecimiento ordenado de las ciudades (Sedesol, 1999); sin embargo, 65\% de la tierra existente era de carácter social (ejidal o comunal), es decir, que no estaba disponible de inmediato debido a que tenía que concluir previamente el Programa de Certificación de Derechos Ejidales (Procede). ${ }^{2}$ De acuerdo con la misma fuente, entre 1983 y 1995, de las 120 mil hectáreas que se habían incorporado al crecimiento urbano, 30 mil lo habían hecho por vías legales y 90 mil lo habían hecho en forma irregular. En este sentido, la capacidad económica y de gestión de las autoridades municipales y estatales para hacer frente a las demandas de los ciudadanos en cuanto a suelo, servicios y equipamiento, por mejor que se encuentren sus finanzas, siempre resultará insuficiente.

Si vemos un poco hacia delante, la situación no parece que será mejor. En el año 2030 se espera que seamos 130 millones de mexicanos. Es decir, en 30 años se tendrá que alojar a 30 millones más de pobladores, de ellos, $80 \%$ será parte de la población urbana, lo que implica que 24 millones estarán demandando servicios urbanos y tierra donde vivir; se calcula que se requerirán por lo menos 700 mil hectáreas de suelo para las nuevas zonas urbanas, lo cual equivale a la extensión actual del estado de Morelos (Zepeda, 2000: 42).

El problema de la vivienda no es un asunto menor. Para el 2020 habrá 38.5 millones de hogares en el país, es decir, 16 millones más que en el año 2000; lo cual significa que la sociedad en su conjunto tendrá que proveerse de una cantidad similar de casas para aspirar a que cada familia habite una vivienda (Her-

\footnotetext{
${ }^{2}$ Como se sabe, el Programa de Certificación de Derechos Ejidales (Procede) tiene como finalidad que la tierra de propiedad social y normada por el derecho agrario sea regularizada mediante su incorporación al marco jurídico del derecho civil, y de esa manera pueda eventualmente formar parte del mercado privado de suelo. Sólo como tierra de propiedad privada, los actuales ejidos pueden incorporarse al crecimiento urbano ordenado.
} 
nández, 2000: 38). Se prevé una necesidad anual de aproximadamente 700 mil viviendas sólo en el sector urbano, cuando en 1999 la oferta formal fue de unas 300 mil unidades (Zepeda, 2000: 43). Así, la oferta de suelo tiene cada vez más importancia en la edificación de la vivienda y de las ciudades, al mismo tiempo que resulta un factor decisivo para el ordenamiento territorial.

El futuro urbano, social, económica y ambientalmente próximo a lo sostenible dependerá en gran medida de nuestra capacidad técnica, social y política para gobernar el crecimiento de las grandes ciudades y para reducir la dispersión de la población, así como para garantizar que el uso que se le otorgue al suelo sea compatible con su aptitud y evitar un mayor deterioro del ambiente. De igual forma, será necesaria una acertada promoción de actividades productivas en regiones y ciudades de acuerdo con su potencial de desarrollo. En todo lo señalado, empero, estamos muy por debajo de las necesidades requeridas.

En síntesis, durante el último tercio del siglo xx vino acentuándose el desfase entre crecimiento urbano y crecimiento económico. Y aunado a que persisten o se agudizan problemas como el de la expansión de la ciudad ilegal y los rezagos financieros y administrativos de los gobiernos locales, ${ }^{3}$ al mismo tiempo surgen aspectos nuevos como el de la complejización de las formas espaciales urbanas y los cambios en el mundo rural periurbano.

\subsection{Complejización de las formas espaciales urbanas y cambios en el mundo rural}

A lo meramente demográfico y económico debe sumarse el hecho de que las formas territoriales están adquiriendo nuevas configuraciones que vuelven más compleja la interpretación de los procesos territoriales, lo mismo que la instrumentación de políticas de ordenamiento. En cuanto a la interpretación, cabe señalar que se observan procesos de urbanización 'difusa' que ha recibido diversos calificativos, donde la tradicional periurbanización alrededor de las grandes ciudades adquiere características diferentes de como sucedía antaño. En la actualidad se ha perdido la separación física, antes nítida entre el campo y la ciudad, al conformarse una especie de archipiélago urbano con crecientes vínculos funcionales entre la ciudad principal y su periferia; de modo

\footnotetext{
${ }^{3}$ Diversos trabajos dan cuenta de esta situación. Véase por ejemplo Wario (2004) y Morales y García (2004).
} 
que la creciente infraestructura del transporte, junto con la relativa cercanía de ciudades medias a las grandes metrópolis nacionales, ha dado lugar a la conformación de sistemas urbanos polinucleares con intensos procesos de metropolización y megalopolización. Constituye el caso paradigmático la región que circunda la zona metropolitana de la ciudad de México; esto, sin embargo, no sólo ocurre en la región central del país, sino que también en torno a otras grandes metrópolis en el Occidente y Noreste.

En suma, los bordes antiguamente precisos entre lo rural y lo urbano se desvanecen, pues el espacio rural periférico, colonizado y desvirtuado en su función original, queda ampliamente afectado también por la onda expansiva metropolitana. La desventaja de ello es que se trata de procesos que no están bien entendidos ni caracterizados y hace falta investigación que provea insumos para la instrumentación de políticas.

Ahora bien, no se trata solamente de un proceso de afectación de la urbanización sobre los espacios rurales: estamos ante una reconversión misma del mundo rural. Para empezar, su tradicional función de proveer alimentos se ve sustituida por la agricultura comercial, en muchos casos de exportación, donde el capital transnacional y sus sistemas productivos reemplazan las economías campesinas más o menos adaptadas a las condiciones ambientales del territorio. Todo ello ha terminado por romper los vínculos directos entre el productor y el consumidor, lo que favorece el despoblamiento del campo, la destrucción del equilibrio en los ecosistemas, la desaparición de culturas campesinas y ganaderas y la pérdida de diversidad agrícola.

Muchos de los espacios liberados de la economía rural por su baja rentabilidad se vuelven zonas residenciales, y así llevan cada vez más lejos los alcances de la movilidad cotidiana de la población. La superposición de espacios administrativos que se ven implicados en los procesos económicos urbanos hacen cada vez más complejo el gobierno y administración de las conurbaciones, de las metrópolis y de las regiones urbanas.

\subsection{El problema de la gestión fragmentada de las metrópolis se acentúa}

Mientras las tareas acumuladas de las autoridades municipales urbanas no han sido cubiertas, aparecen nuevos retos de gobierno y de administración. Cierto que el problema no es nuevo, 
pero sí es cada vez de manejo más difícil; no por el tamaño alcanzado por las áreas metropolitanas, sino por la complejidad que le confiere el hecho de estar ocupando distintas unidades territoriales administrativas. Así, desde el punto de vista institucional y político está pendiente, primero, resolver la situación de un municipio que no ha alcanzado su autonomía política plena ni financiera; para en un segundo momento, trabajar en la gestión coordinada de los asuntos metropolitanos.

Hasta ahora, la gestión de las metrópolis ha sido fragmentada, con la agravante de que cada vez se agregan más municipios por la sola expansión de las áreas conurbadas, con lo cual crecen a su vez los problemas de superposición de competencias; ${ }^{4}$ los municipios representan escalas limitadas de gobierno para un espacio social y procesos urbanos sin limites definidos, ya que lo metropolitano abarca unidades político-administrativas incluso entre fronteras estatales e internacionales. De hecho, la sola definición y delimitación de lo metropolitano constituye un problema no resuelto, aunado a que las áreas metropolitanas son asociaciones cambiantes en el tiempo; constantemente están en entredicho sus límites territoriales y administrativos (véase Rodríguez y Oviedo, 2001: 41).

Ante una indefinición conceptual y una delimitación confusa de las metrópolis, por consiguiente, las opciones de gobierno y administración se complican tanto desde el punto de vista operativo como desde el político. Así lo muestran Rodríguez y Oviedo (2001: 5) cuando analizan las modalidades conocidas de gobierno de las áreas metropolitanas: el gobierno tipo supramunicipal y el gobierno tipo intermunicipal. Promover uno u otro modelo de gobierno -señalan- no resulta sencillo, ya que lo que ambos implican es una reestructuración institucional y por lo tanto del poder en cualquier país (véase también Lefevre, 1999: 8).

En el caso mexicano, por ejemplo, ¿̇puede imaginarse el peso político que tendría una autoridad metropolitana que abarcara algunas entidades federativas, o fragmentos de ellas, donde se concentrara un tercio de la población nacional, un tanto igual del PIB total y dos quintas partes del producto industrial? Ade-

${ }^{4}$ Esto se traduce en tres tipos de contradicciones para abordar los diversos problemas: 1) los de carácter técnico, cuando se trata del abastecimiento y expulsión del agua, por ejemplo; 2) los de carácter político, cuando coinciden en una misma aglomeración distintos partidos políticos en los diferentes niveles de gobierno, y 3) los de tipo económico-financiero, cuando las necesidades y los recursos no coinciden en un mismo territorio (Pírez, 2002). 
más, ¿cómo se delimitaría la metrópolis?, ¿̇a quién representaría el nuevo nivel de gobierno?, ¿cómo se articularía con los otros niveles?, ¿cuáles serían sus atribuciones? Se requeriría, entre otras cosas, una legislación que se superpondría a la de los municipios, estados y gobierno federal, cuestión nada sencilla.

A lo anterior hay que añadir que lo metropolitano no forma parte del sentido común de los ciudadanos y autoridades (UN, 1995: 63). "La racionalidad predominante reconoce los problemas por sectores (vivienda, agua, electricidad, caminos), o en el ámbito del barrio y de la comuna, pero no efectivamente en una dimensión territorial extensa o variable" (Rodríguez y Oviedo, 2001: 8).

Otro aspecto notable de la gestión metropolitana es la paradoja que plantean las propuestas para gobernarlas, porque nos ponen ante la disyuntiva de una mayor o menor concentración del poder; es decir, mientras que en los últimos años lo que ha venido demandándose desde los partidos políticos es una descentralización de funciones de gobierno hacia los municipios, lo que parece imponerse como necesidad es la cesión de ciertas atribuciones de éstos a otras entidades que no existen. Por eso las iniciativas de cambio de gestión metropolitana en el ámbito internacional no constituyen una demanda de los gobiernos municipales, y ni siquiera de la ciudadanía, sino que surgen del gobierno central.

Pírez (2002) considera que hay una sobrevaloración de lo metropolitano, por lo cual lo procedente es consolidar la autoridad municipal y establecer mecanismos efectivos de coordinación. Pero en caso de ser necesaria una nueva estructura política, ésta, de acuerdo con Lefevre (2000, en Rodríguez y Oviedo, 2001: 11), sólo es válida si posee las siguientes características: 1) autonomía financiera y de inversión, pero con controles; 2) autoridad basada en la legitimidad que otorga el voto ciudadano; 3 ) competencias precisas, y 4) responsabilidad legal ante la ciudadanía. Hasta el momento en muy pocos casos se cumplen dichas condiciones. Por si esto fuera poco, lo metropolitano, entendido como la gravitación de un área en torno a una ciudad central, parece ya no operar del todo cuando lo que se observa es la conformación de conurbaciones de áreas metropolitanas en grandes regiones urbanas, con diferentes centros principales de actividades.

En síntesis, la gestión fragmentada de las metrópolis en México es un problema complejo que se acentúa, y que tiene facetas que van de lo técnico a lo administrativo, a lo sociológico y a lo polí- 
tico. A las limitantes de siempre de un municipio tradicional sin peso político y fuerza económica -en su inmensa mayoría-, se le suman formas espaciales difusas en constante expansión a las que no corresponde un solo nivel de gobierno; de ahí que no haya condiciones ni mecanismos que permitan el desarrollo de los modelos organizativos de los gobiernos metropolitanos (Rodríguez y Oviedo, 2001: 39). Mientras tanto, persisten los problemas estructurales de incapacidad institucional de proveer suelo apto para el desarrollo urbano ordenado.

\subsection{La persistencia de los problemas estructurales en la construcción de la ciudad}

La gestión efectiva de la tierra es una condición para el desarrollo económico y social. Sin embargo, el problema más serio de las ciudades mexicanas es su crecimiento irregular y anárquico vinculado en gran medida a la pobreza, hechos que obedecen al incumplimiento de las diversas leyes y ordenamientos urbanísticos, así como a la carencia de servicios e infraestructura básica por falta de inversión pública. El conflicto en consecuencia es, por una parte, institucional, en lo que se refiere al incumplimiento del Estado de derecho y de las normas urbanísticas; pero por otra parte y principalmente, es una deficiencia estructural de los mercados para ofrecer suelo a los habitantes a precios accesibles y con servicios. En este sentido, el problema no es el suelo en sí mismo (si bien los precios son exagerados), la verdadera dificultad es servir al suelo (Smolka, 2001), por lo que el concepto de informalidad debe dejar de utilizarse en sentido peyorativo para referirse a asentamientos populares solamente, ${ }^{5} \mathrm{y}$ debe considerarse también informal todo aquel que carezca de servicios e infraestructura, donde el Estado y los gobiernos locales tienen su responsabilidad.

Ahora bien, otro aspecto también estructural que tiene que ver con lo anterior es el de las características del bien vivienda y de la industria de la construcción. En efecto, el suelo equipado y la vivienda, como ya lo había señalado Castells (1974: 179-186), responden a una relación entre oferta y demanda, razón por la cual históricamente ha existido una penuria de dicho bien y de equipa-

\footnotetext{
${ }^{5}$ Es menester señalar que la irregularidad de los asentamientos urbanos está en todos los niveles socioeconómicos y no sólo en $60 \%$ de las clases populares; esta condición también es una característica de los asentamientos de clase media alta y alta en un elevado porcentaje.
} 
miento colectivo en los países subdesarrollados. Este autor ya advertía entonces que el desarrollo de vivienda depende de las características y objetivos de la industria de la construcción; de manera que en ausencia de intervención pública, la única demanda efectivamente considerada será la demanda solvente.

En un caso como en el otro (suelo y vivienda) es imposible resolver la crisis únicamente por los mecanismos del mercado. Son indispensables instrumentos fiscales en el caso del suelo y programas crediticios y subsidios en el caso de la vivienda -pues no hay prácticamente producción privada de vivienda 'popular'-, pero sobre las propuestas nos ocuparemos en otro trabajo. ${ }^{6}$

Cabe reiterar que en México el régimen de propiedad de la tierra sigue siendo una limitante en sí misma, ya que choca con las exigencias del crecimiento urbano ordenado; el predominio de tierra de propiedad social, como ya se ha dicho, dificulta el control sobre el crecimiento urbano. A ello se debe que gran parte de los residentes no tengan derechos claros de propiedad o no los hayan tenido en algún momento, con lo cual se alimenta el círculo vicioso de falta de servicios y pobreza financiera de los municipios. Polèse (1998: 101) expone muy bien la situación:

[...] ¿cómo financiar la infraestructura pública (agua, alcantarillado, apertura de calles, etc.) si no se cobran anticipadamente los impuestos prediales (u otros derechos) sobre las propiedades? Pero si los derechos de propiedad no son claros, resulta difícil cobrar impuestos prediales; además, una imposición "justa" de impuestos prediales requiere tener al día un registro catastral con evaluaciones "honestas" del valor de mercado de los terrenos. Para llevarse a cabo exitosamente, la urbanización exige un régimen claro de derechos, y aparatos de Estado eficientes (en sus niveles nacional y local).

No existen, entonces, fuentes de financiamiento para el desarrollo urbano ordenado, sobre todo donde se asientan los sectores populares; como tampoco hay una congruencia institucional para atender los problemas que de ello se derivan. Por ejemplo, las secretarías, subsecretarías, departamentos, etc., que tienen a cargo vigilar que los asentamientos cumplan la normatividad urbanística, no tienen mayor incidencia en la reglamentación de las instituciones que abastecen de servicios a dichos asentamientos, ni para quienes los reglamentos urbanos no cuentan; este es el caso

${ }^{6}$ Ciertamente ha habido un incremento notable de producción de vivienda social en el actual sexenio, pero se trata de una oferta para el sector asalariado de los trabajadores, por lo cual se atiende un 'derecho de clase': la 'clase asalariada', que cada vez tiene una menor participación relativa en el total de trabajadores del país. 
de las empresas proveedoras de agua potable y energía eléctrica. Así, se desanima a los habitantes la regularización de sus predios, se reduce la recaudación de impuestos y se debilita a las instituciones. Sin embargo, a quienes menos debe responsabilizarse es a los habitantes.

No es de extrañar que los mecanismos de incorporación de suelo al desarrollo urbano con carácter 'preventivo', en particular los programas de reservas territoriales de los años ochenta y del sexenio 1994-2000, hayan tenido resultados muy limitados (Olivera, 2001).

Para concluir, mientras las superficies urbanas se han desbordado y las áreas de trabajo de las instituciones del sector urbano y los gobiernos municipales se han multiplicado, sus atribuciones y alcances se han mantenido con pocos cambios reales, o han sido insuficientes.

\section{El marco jurídico legal y la institución municipal en la gestión del desarrollo urbano}

Aunado al desfase entre crecimiento urbano y desarrollo económico, la incapacidad que en general han mostrado las autoridades municipales en la gestión de las ciudades remite necesariamente a varios aspectos laterales con notables imbricaciones, y en algunos casos con fuertes raíces históricas. En primer lugar tiene que ver el origen de la institución municipal, asociado al tipo de régimen político y a un determinado modelo de gestión pública (o de implantación de políticas); esto, además, vinculado con otros referentes institucionales, en particular el marco jurídico legal y su (in)cumplimiento mediante el (no) ejercicio del Estado de derecho.

En segundo lugar sobresale la condición impuesta e insatisfactoria de la reforma del Estado, donde el gobierno local, más que órgano complementario de los otros niveles de gobierno, ha querido verse como un ente supletorio de ellos sin contar con todos los atributos y cualidades necesarios. Por eso pueden calificarse de insatisfactorios los resultados de la política de descentralización y de las diversas reformas al Artículo 115 constitucional a partir de los años ochenta, en particular lo que tiene que ver con la planeación del desarrollo urbano y la promoción del crecimiento económico de las ciudades, que son una misma cosa.

Adicional a lo anterior, se encuentra el peculiar conflicto que ha afectado a los municipios en su tarea de gestión del desarrollo 
urbano, y que es la oposición entre los artículos 115 y 27 constitucionales. Este es un conflicto que surgió al finalizar la gesta revolucionaria de inicios del siglo $\mathrm{xx}$, y que no se ha superado aun con la reforma de 1992 al Artículo 27.

\subsection{Institución municipal, régimen político y tipo de gestión pública}

El municipio mexicano nació subordinado a las necesidades de la corona española durante el periodo colonial del país, y se mantuvo subordinado a los gobiernos federal y estatal en las distintas etapas posteriores a la guerra de independencia. Así, desde su origen en el siglo XVI -con antecedentes precolombinos-, el municipio ha sido una entidad hecha para administrar y no para gobernar; y aun con los cambios constitucionales realizados en el último cuarto del siglo xx, la situación en lo general no ha cambiado. Fueron más de 400 años durante los cuales se forjó una relación autoritaria y dependiente entre los tres órdenes de gobierno.

Una de las causas primordiales de que incluso en el siglo Xx las condiciones del municipio no se hayan modificado fue el tipo de régimen político posrevolucionario dominante, que ha sido calificado como "democrático desde el Estado" desde los años cuarenta hasta los años ochenta, y "en transición democrática" a partir de los noventa. Desde estos esquemas, Cabrero (2000a: 200) ubica al régimen político mexicano en un bajo nivel de permeabilidad hacia la opinión pública y las demandas sociales, con un predominio de relaciones intergubernamentales de tipo vertical. Al aplicar su análisis al estudio de las políticas públicas, encuentra que las estructuras de gobierno no fueron diseñadas para ser permeables, por lo que aun en el escenario de transición política (y reforma del Estado) que se vive actualmente, no es posible que dicha estructura se abra -incluso los mismos actores, dice, no están orientados hacia una lógica de apertura.

Se tiene así una combinación de exclusión de las demandas sociales y una relación predominantemente jerárquica subordinada entre órdenes de gobierno, que resulta adversa a los objetivos de todo tipo de política pública, en que sobresalen las políticas urbanas.

7 Aunque también puede llamársele "federalismo estatista" (cfr. Hernández, 1996: 30). 
La poca permeabilidad entre el régimen político y las demandas sociales ha tenido como efecto un tipo de gestión pública singular, caracterizada por el escaso aprendizaje obtenido de la aplicación de las políticas gubernamentales, debido sobre todo a la falta de evaluación que se hace de ellas, junto con el difícil acceso a la información respectiva por ser un monopolio estatal. ${ }^{8}$ Esto impide mejorar la gestión pública, ya que puede desviarse con facilidad la orientación de las políticas (Cabrero, 2000a: 209).

Hay otros referentes institucionales, prácticas y reglas que, ubicadas en el terreno de la ambigüedad, han acentuado las características de centralismo y verticalidad en la elaboración de las políticas públicas, y de pobres resultados en su ejercicio. Se trata de varias situaciones incompatibles con una gestión pública eficiente; sobresale, ante todo, la existencia de un marco jurídico-legal, a veces impreciso y siempre negociable, que ha derivado en la inexistencia de un verdadero Estado de derecho. En este escenario de laxitud institucional y de inexistencia de rendición de cuentas, los compromisos de los servidores públicos no son con la institución y la sociedad, sino con la 'camarilla'; la transparencia se simula en gran medida; las evaluaciones se improvisan; los servidores públicos se estancan en un bajo nivel de profesionalización, y la incertidumbre es el escenario que prevalece (Cabrero, 2000a: 212).

Ahora bien, si, como hemos venido haciendo, nos referimos más en detalle a los problemas urbano-regionales, es importante explicar en qué momento surgen y cómo van desarrollándose las contradicciones jurídicas e institucionales que han impedido que el municipio haya tenido capacidad plena -únicamente en estos términos- para un desempeño satisfactorio de sus funciones. Esto lo hacemos con base en el análisis de los artículos 27 y 115 constitucionales en sus distintas etapas de evolución.

Debe señalarse que se han dado pasos importantes para modificar la situación imperante. Uno de ellos es la Ley Federal de Transparencia y Acceso a la Información Pública Gubernamental, el otro es el inicio de una política de evaluación de las políticas públicas. El primer caso, donde se señala que toda información del gobierno es pública, salvo la que sea considerada como clasificada, es considerado como un avance de la ciudadanía en el terreno de la reforma del Estado, sin que por ello se agote el tema. Al finalizar el sexenio actual sabremos qué resultados habrán tenido estas importantes iniciativas. 


\subsection{El artículo 115 constitucional, la reforma del Estado y la planeación urbana}

\subsubsection{Antecedentes}

El carácter subordinado del municipio mexicano a la metrópoli colonial no se modifica con el fin de esta etapa histórica, le sigue una sumisión al gobierno federal durante la primera república independiente en el siglo XIX, y de ahí en adelante. En efecto, durante el siglo XIX, tanto en la constitución de 1824 como en la de 1857 se establece y reafirma respectivamente al municipio como base del federalismo; sin embargo, la inestabilidad política de una nación que recién acababa de fundarse primero, y el carácter coercitivo del gobierno federal sobre los niveles inferiores de gobierno después, impiden la conformación de un federalismo cooperativo en el país que pervive hasta nuestros días.

Así, desde su origen, el Estado mexicano se ha visto sometido a una tensión entre federalismo y centralismo por una parte, y entre libertad y poder por la otra, donde los estados y los municipios, pero sobre todo estos últimos, han sido los más afectados en términos de pérdida de autonomía (poder) ante el gobierno central (o ante el gobierno estatal cuando así corresponde). En otros términos, el federalismo deseable está asociado a una mayor libertad política de los gobiernos municipales para ejercer sus atribuciones, y no sólo a una mayor capacidad económica o administrativa como se había planteado en distintas reformas. No obstante, esta ha sido la fórmula utilizada tradicionalmente por el gobierno central mexicano para relacionarse con los otros dos niveles de gobierno; es decir, se ha hecho equivaler federalismo con la dimensión económica y social del desarrollo local, y en particular con la posibilidad de que la población acceda a servicios públicos como educación, salud, comunicaciones, etc., dejando a un lado la parte de libertad política únicamente como concesión y autolimitación (cfr. Hernández, 1996 y Aguilar, 1996).

Lo anterior originó el llamado federalismo coercitivo o estatista -según el momento- que, enmarcado en una sociedad corporativa, conformó un desequilibrio entre el avance de los derechos sociales de la población más los derechos políticos de los municipios, y el estancamiento los derechos civiles, mercantiles y electorales de los ciudadanos. Hernández (1996) ilustra muy claramente esto para los siglos XIX y Xx. Entre 1867 y 1890 , por ejemplo, el federalismo se afirmó por la expansión de las comu- 
nicaciones, la internacionalización de la economía y el progreso material de los territorios estatales por mayor difusión de bienes públicos; sin embargo, ello fue posible gracias a una creciente centralización política y administrativa que después no pudo sostenerse en el último tramo de la centuria, lo que tuvo como resultado una devaluación del federalismo, primero, y el rompimiento del marco institucional después (Hernández, 1996: 27).

Con el movimiento revolucionario de 1910-1917, ante la demanda de mayor libertad municipal, soberanía estatal, sufragio efectivo y voto directo, hay una renovación del pacto federal. Nuevamente, empero, desde los años treinta hasta los sesenta y luego de un periodo de inestabilidad, ocurre "una especie de intercambio de libertad política por protección social” y gobernabilidad (Hernández, 1996: 29); es decir, la libertad política pasa a un segundo término, mientras que el aumento del gasto social es destinado a cubrir programas de protección social así como la dotación de servicios públicos.

Nuevamente se incurre en el error de coartar la libertad política de los ciudadanos y restringir sus derechos civiles a cambio de un impulso a la modernización económica de la nación, con el agravante de que se practica un federalismo corporativo sustentado en la burocratización y en la prestación de los servicios, así como en su condicionamiento. En este esquema, tanto los municipios como los estados vieron afectadas sus finanzas de manera importante. Esta falta de democracia con predominio del centralismo, en consecuencia, se manifestó en conflictos sociales desde fines de los años cincuenta y sobre todo en los años sesenta.

De entonces a la fecha, durante las crisis del sistema político, el Estado ha practicado la fórmula de autolimitarse para mantener poder, al confundir el federalismo con la simple descentralización administrativa o la simple desconcentración de aparatos administrativos o de decisiones administrativas hacia los estados y municipios (Hernández, 1996: 33). El análisis de las últimas reformas al Artículo 115 corroboran lo anterior, si bien pueden observarse algunas modificaciones en la reforma de 1999. 
2.2.2 Las reformas más recientes al Artículo 115: La reforma de 1976 y la institucionalización de la planeación urbana (sexta reforma $)^{9}$

Una primera reforma importante al Artículo 115 constitucional, en cuanto a que coincide con un primer replanteamiento de las tareas municipales en la conducción del desarrollo urbano, es la de 1976, que es el año en que precisamente se inicia el proceso de institucionalización de la planeación urbana con la publicación de la Ley General de Asentamientos Humanos. La elaboración de la ley implicó también reformas a los artículos 27 y 73 .

Con las modificaciones al Artículo 115, se concedió a los municipios capacidades para expedir leyes, reglamentos y disposiciones administrativas de ordenamiento de los asentamientos humanos, así como llevar a cabo funciones de planeación de las conurbaciones interestatales. De hecho, se introdujo por vez primera el concepto de conurbación, entendida como la continuidad geográfica de un centro de población urbano situado en territorios de dos o más municipios.

Las reformas y adiciones al Artículo 27 le otorgaron a la nación el derecho permanente de imponer a la propiedad privada las modalidades que dicte el interés público, para regular en beneficio social el aprovechamiento de los elementos naturales susceptibles de apropiación. También se introdujo el concepto de desarrollo armónico y equilibrado y el mejoramiento de las condiciones de vida de la población urbana pues se preveía el dictado de medidas para ordenar los asentamientos humanos mediante provisiones, usos, reservas y destinos de tierras, aguas y bosques, para planear y regular la fundación, conservación y mejoramiento de los centros de población.

Con los cambios al Artículo 73, se hace posible en lo sucesivo la concurrencia de la federación, los estados y los municipios en el ámbito de sus respectivas competencias en materia urbanística. Otras medidas fueron las modificaciones a la Ley General de Bienes Nacionales y a la Ley de Obras Públicas. No obstante, la culminación de las reformas fue la aparición de la Ley General de Asentamientos Humanos (LGAH).

No es propósito de este trabajo evaluar la LGAH; para eso puede revisarse Azuela (1989a); sólo nos interesa remarcar que re-

${ }^{9}$ Las reformas anteriores ocurrieron en el siguiente orden: primera reforma, $20 \mathrm{de}$ agosto de 1928; segunda reforma, 29 de abril de 1933; tercera reforma, 8 de enero de 1943; cuarta reforma, 12 de febrero de 1947, y quinta reforma, 17 de octubre de 1953. 
presentó la unificación de las acciones públicas emprendidas en el ámbito urbano-regional. Sin embargo, dadas las condiciones del municipio y la crisis económica que se vino en los ochenta, no se tuvo la capacidad para enfrentar los problemas derivados del crecimiento urbano.

Un aspecto en particular que debe destacarse es que a partir de los cambios anteriores se reveló un conflicto institucional muy serio entre las instituciones del sector agrario y las instituciones del sector urbano, bien documentado por Azuela (1989b) principalmente, y que se reflejaba cotidianamente en la frontera de la ciudad donde el suelo ejidal era al mismo tiempo no sólo el límite de la ciudad, sino el límite jurisdiccional de las autoridades encargadas del desarrollo urbano. Sobre ello, no obstante, volveremos más adelante.

\subsubsection{La reforma de 1977 (séptima reforma)}

Esta reforma fue eminentemente política, ya que su razón primordial fue introducir el principio de representación proporcional en los ayuntamientos, con la finalidad de ampliar la participación de las fuerzas políticas y sociales minoritarias en la vida política nacional.

\subsubsection{La reforma de 1983 (octava reforma)}

Fue una reforma de gran importancia: redefinió el papel del municipio en la estructura del sistema federal mexicano al determinar sus fuentes de ingreso, los servicios públicos a su cargo y reconocer su 'autonomía'. Asimismo, es considerada como una reforma eminentemente urbana debido a que las atribuciones y recursos señalados en el texto tenían como finalidad principal permitir a los municipios conducir el desarrollo urbano; desde entonces, los ayuntamientos supuestamente pueden: formular, aprobar y administrar los planes de desarrollo municipal; controlar y vigilar la utilización del suelo; participar en la instauración y administración de reservas territoriales y zonas ecológicas; intervenir en la regularización de la tenencia de la tierra, y otorgar licencias de construcción y permisos. Asimismo, se especificaban los servicios públicos a cargo de las autoridades municipales: agua potable, alcantarillado, alumbrado público, limpia, mercados y control de abasto, panteones, rastro, calles, parques y jardines, seguridad pública y tránsito. 
En otro sentido, la reforma privilegió lo económico sobre lo político, ya que uno de sus aspectos más importantes fue poner al alcance de los municipios la posibilidad de disponer de nuevos recursos económicos mediante el cobro del impuesto predial, así como determinar sus presupuestos de egresos. Al mismo tiempo, sin embargo, las legislaturas estatales recibían facultades que restringían la autonomía política y el autogobierno de los municipios; así, éstas podían suspender o desaparecer un ayuntamiento, o revocar el mandato de algunos de sus miembros; también tenían la facultad de aprobar los ingresos de la hacienda municipal; e incluso, les favoreció la imprecisión de la fracción 111 sobre la 'concurrencia' o 'convenio' para la prestación de los servicios públicos de competencia municipal entre el gobierno de la entidad federativa y los ayuntamientos, según lo determinaran las leyes locales.

Ahora bien, a pesar de que se privilegió lo económico, no se atacó la penuria de recursos para el funcionamiento del quehacer municipal, más bien se acentuó el carácter 'dependiente y residual' en las entidades federativas. En los hechos, los ayuntamientos quedaron subordinados a los gobernadores, mientras que la relación entre gobiernos estatales y el gobierno federal no se modificó.

En efecto, la descentralización en materia de desarrollo urbano no significó la renuncia de facultades o recursos por parte del gobierno federal a favor de los gobiernos estatales, sino una reducción de las facultades de éstos a favor de los ayuntamientos (Azuela, 1988: 10). Sin embargo, aclara Antonio Azuela, las legislaturas estatales retuvieron el poder y las funciones en policía y buen gobierno en la prestación de servicios públicos y, por medio de los convenios estipulados en la reforma, mantuvieron muchos de ellos la administración de algunas fuentes de ingreso municipal (como el predial), y compartieron con los municipios la facultad de aprobar los planes de desarrollo urbano, el control de los usos del suelo y la autorización de licencias y permisos de construcción y fraccionamientos.

Por otra parte, aunque la reforma municipal de 1983 fue la primera en la cual se tocaron aspectos de fondo que afectan el desenvolvimiento de los municipios en México, fue, como señaló Massolo (1991: 24), una reforma huérfana de movimientos sociales ciudadanos reivindicativos de ayuntamientos democráticos y de descentralización de los poderes públicos. En este sentido, se trató de una reforma no pedida, que sucede en un con- 
texto de crisis económica (fiscal y administrativa del gobierno federal), de poca pluralidad política en los ayuntamientos y, por consiguiente, una reforma desde arriba monopolizada por el Poder Ejecutivo. El slogan del gobierno acerca de la "descentralización de la vida nacional" obedecía a su incapacidad para seguir sosteniendo los gastos de inversión y financiamiento del desarrollo de los estados y regiones del país, como venía haciéndolo décadas atrás; así, se reduciría la sobrecarga fiscal y administrativa del gobierno federal para en su lugar fortalecer la capacidad económica, administrativa y política de los estados y municipios (cfr. Aguilar, 1996: 110).

El Estado, en síntesis, se vio en la necesidad de modernizarse y someterse a un ajuste que implicaba su achicamiento y por tanto la reducción de sus responsabilidades como participante directo en el desarrollo de actividades productivas para quedar solamente como promotor; de ahí que la desregulación económica y la privatización de las empresas públicas pasaran a ocupar un papel relevante a partir de entonces, junto con la descentralización de la administración.

Por lo anterior la descentralización fue considerada por algunos estudiosos como un proyecto modernizador neoliberal de la economía y del propio Estado, donde lo que interesaba no era la democratización del poder o de las relaciones Estado-sociedad civil, sino cumplir con objetivos de descentralización, participación, eficacia y racionalidad del gasto público (Massolo, 1991: 16). Coraggio (1991: 57) adjudicó a la descentralización los sinónimos de privatización, desregulación, participación-autogestión, participación-control del Estado, reconocimiento de particularidades y construcción de consensos desde las bases.

Sin embargo, la propuesta de descentralización de la vida nacional funcionó, por lo que a partir de entonces se consideraron muy positivas la descentralización administrativa del Estado hacia los gobiernos locales y la participación ciudadana; de ahí que tienda a asociarse la cuestión municipal con el poder local. Empero, advierte Restrepo (2001: 94), erróneamente se ha llegado a identificar al gobierno local como una instancia permeable y accesible a las necesidades de los sectores populares y a las prácticas participativas como sinónimo de democracia. Al contrario -dice-, descentralización y participación sólo pueden ser entendidas en el contexto de la reestructuración capitalista: "son las formas espaciales de organización administrativa y política de la sociedad capitalista actual”. 


\subsubsection{La reforma de 1987 (novena reforma)}

Únicamente sirvió para establecer la exclusividad del Artículo 115 constitucional para atender la cuestión municipal, al transferir todos los demás ordenamientos referentes al régimen interior de los estados al Artículo 116.

\subsubsection{La reforma de 1999 (décima reforma)}

Se retoman los resultados de la reforma de 1983, pero en un contexto de transición democrática y pluralidad política que en aquella ocasión no existía. Los obstáculos todavía prevalecientes para la modernización de los gobiernos municipales, la renovación del federalismo y la reestructuración del propio gobierno federal hacían ineludible retomar el tema de la reforma municipal.

Aunque para ser más precisos, hay que mencionar que la manera en que se expresa la reforma en el texto constitucional revela varios aspectos importantes de la situación política que se vivía en esos años. Sobresale, en este sentido, el hecho de que la reforma ocurre en el momento en que por primera vez -a raíz de las elecciones federales de 1997- el Partido Revolucionario Institucional (PRI) no es mayoría en la Cámara de Diputados, pero donde la mayoría numérica de la oposición era muy precaria; de tal suerte que el texto final fue producto de la negociación entre el Partido Acción Nacional (PAN), como segunda fuerza y como proponente de la reforma, y el PRI. De ahí que su contenido pueda considerarse, nuevamente, acotado. Esta acotación se refiere no sólo a las limitaciones que se impusieron a la propuesta original del PAN, sino también y sobre todo, a que con la reforma no se logra trascender el modelo cupular y centralista del proceso legislativo, prueba de ello es que los representantes de los ayuntamientos estuvieron ausentes del debate parlamentario, al igual que las organizaciones sociales relacionadas con el tema ( $c f r$. Guillén y Ziccardi, 2004: 16).

A pesar de lo señalado, un balance de la reforma indica que ésta tuvo algunas virtudes, ya que se fortalece al municipio frente al estado, al reconocérsele el carácter de órgano de gobierno con competencias exclusivas que sólo el ayuntamiento puede transferir a los gobiernos estatales si así conviene a sus intereses (Guerrero, 2000: 232). Otro avance reconocido es que, si bien se introduce el concepto de leyes estatales, éstas tienen objetos y limitaciones definidas, por lo que la competencia reglamentaria 
del municipio se hace exclusiva para aquellos aspectos propios de su competencia. Igualmente, el presidente municipal conserva el mando de las policías preventivas municipales; las empresas paraestatales quedan obligadas al pago del impuesto predial al ayuntamiento; queda garantizado el derecho de iniciativa municipal en materia tributaria y, finalmente, se fortalece (legalmente) el carácter fiscalizador de las legislaturas locales en las finanzas municipales, para fortalecer el contrapeso al poder del ayuntamiento en la asignación y operación presupuestal.

Por el lado de las carencias de la reforma (Guerrero, 2000: 233), destaca la omisión sobre la conveniencia de que el ayuntamiento pudiera aprobar las bases de las contribuciones inmobiliarias, que le permitiera al municipio su actualización para una mejor recaudación del impuesto inmobiliario. Tampoco se eliminó el candado que impide la reelección inmediata de los presidentes municipales; no se obligó a los estados a reconocer la heterogeneidad del mapa municipal ni a mejorar los términos de representatividad de la sociedad, ni a dar mayor autonomía a la administración municipal frente al cabildo (para mejorar supervisión por un lado y ejecución por el otro); no se aludió al establecimiento de un sistema nacional de información fiscal (oportuna, accesible, transparente, etc.); no se integró al municipio a foros de discusión sobre el sistema de transferencias (Sistema de Coordinación Fiscal); no se reconoció al municipio como autoridad fiscal, y por último, no se obligó a los estados y a la federación a transferir los recursos financieros oportuna y transparentemente. No se trató, tampoco, el asunto de la preparación y formación de administradores, funcionarios y políticos que participan en la gestión municipal.

A pesar de sus logros, por consiguiente, y al igual que la de 1983, es una reforma acotada que sigue mostrando la tensión entre centralización-descentralización y poder-libertad, pues los avances del municipio son a costa de los gobiernos estatales, mientras que el gobierno federal vuelve a quedar igual. Esto es claro particularmente en lo que tiene que ver con la exclusividad de las competencias municipales -las cuales en su mayoría ya existían-, donde se marca que no pueden intervenir en ellas los gobiernos estatales, a menos que convenga a los intereses del municipio, y no del estado, como anteriormente ocurría.

El carácter acotado de la reforma es claro en las implicaciones que tiene para la planificación urbana, en el sentido de que el municipio, a pesar de obtener el reconocimiento como nivel de 
gobierno y haberse transformado por lo tanto de un modelo de relaciones intergubernamentales bipartita a otro tripartita, se mantiene subordinado sobre todo al gobierno federal, cuando en lugar de administrar los servicios sobre los que recibió exclusividad, tiene que participar en programas de política social o de obra pública nacionales.

En esta línea de relaciones intergubernamentales, los municipios dependerán de su capacidad de negociación para, por un lado, recuperar las capacidades que el nuevo Artículo 115 les confiere, pero que están bajo control de los ejecutivos estatales, y por otro lado, convenir la administración de sus facultades exclusivas con los funcinarios estatales. El detalle aquí, tal como lo señala Guillén (2000: 252), es que la posibilidad de negociación se restringe a lo que ya le es propio a los municipios, lo cual no puede considerarse un gran avance en su capacidad de interlocución con otros niveles de gobierno.

Si la reforma resulta acotada para las propias capacidades exclusivas del municipio, lo es también en el caso de la fracción v; aquí se acepta la relación intergubernamental del municipio en ciertas áreas donde se establece su intervención directa, pero se omite su participación en otras que también son de importancia para la planificación. Por ejemplo, el municipio tiene facultades completas en los incisos: a) formular, aprobar y administrar la zonificación y planes de desarrollo municipal; b) autorizar, controlar y vigilar la utilización del suelo, en el ámbito de su competencia, en sus jurisdicciones territoriales, y c) otorgar licencias y permisos para construcciones. En otros incisos, su participación es restringida: a) participar en la conformación y administración de sus reservas territoriales; b) participar en la formulación de planes de desarrollo urbano regional, los cuales deberán estar en concordancia con los planes generales de la materia; c) intervenir en la regularización de la tenencia de la tierra urbana; d) participar en la formación y administración de zonas de reservas ecológicas y en la elaboración y aplicación de programas de ordenamiento en esta materia; e) intervenir en la formulación y aplicación de programas de transporte público de pasajeros cuando aquéllos afecten su ámbito territorial, y f) celebrar convenios para la administración y custodia de las zonas federales. En otras palabras, los ayuntamientos son un gobierno reconocido sólo para determinadas áreas de interés público.

En el caso de la propiedad inmobiliaria ocurre algo parecido a lo anterior, ya que los ayuntamientos sólo podrán proponer a le- 
gislaturas estatales las cuotas y tarifas aplicables a impuestos, derechos, contribuciones de mejoras y las tablas de valores unitarios de suelo y construcciones que sirvan de base para el cobro de las contribuciones. Al respecto, en un quinto artículo transitorio se emplaza a las legislaturas de los estados, en coordinación con los municipios respectivos, a que antes del inicio del ejercicio fiscal de 2002 adoptaran las medidas conducentes a fin de que los valores unitarios de suelo que sirven de base para el cobro de las contribuciones sobre la propiedad inmobiliaria sean equiparables a los valores de mercado de dicha propiedad, y adecuar las tasas aplicables para el cobro de las mencionadas contribuciones para garantizar su apego a los principios de proporcionalidad y equidad.

Ahora bien, aunque la reforma al Artículo 115 era necesaria, también cabía esperar que por sí sola fuera suficiente, considerando que no es el único artículo que regula las relaciones entre los tres ámbitos de gobierno, y porque hay confusión al respecto, hay vacíos y hay centralismo (Guerrero, 2000: 224). El Artículo 26 constitucional, por ejemplo, se refiere a la necesidad de que el gobierno federal establezca convenios con los gobiernos estatales en materia de planeación, y esto podría ser un sustituto a las asociaciones de municipios (Cabrero, 2000b: 61); "una transformación al federalismo es hacer un cambio integral y no únicamente significa modificar el 115" (García, 2000: 63). A este artículo cabría agregar también el 73 y el 27.

En términos operativos, por otra parte, la reforma sólo se había cumplido en el ámbito federal en un sentido, pues quedaban pendientes las modificaciones a otras leyes federales. Había que esperar también una segunda fase que tiene que ver con la modificación de las constituciones de cada estado de la república. Por primera vez, a las legislaturas estatales se les presentaba la oportunidad y responsabilidad de adaptar el contenido de la reforma federal a sus necesidades específicas; es decir, dadas las condiciones políticas del país - de mayor pluralidad política y en transición democrática en comparación con 1983-, se esperaba una pluralidad de reformas en cada estado, que potenciaran a su favor las modificaciones al texto constitucional. Aunque también se especulaba con la posibilidad de que, dada la tradición de agudo centralismo, las legislaturas estatales simplemente se restringieran a copiar la reforma federal y en vez de tener reformas innovadoras hubiera reformas limitadas. En todo caso, está pendiente un análisis por- 
menorizado de dichos cambios, sobre los cuales haremos una breve mención en la última sección del trabajo.

La reforma proporciona elementos para la innovación en el momento en que asigna a las legislaturas estatales la responsabilidad de las "leyes en materia municipal" de las cuales se derivarán la reglamentación, la organización administrativa y de los servicios públicos y la participación ciudadana. En opinión de Guillén (2000: 248), los congresos estatales tienen la posibilidad de impulsar la modernización del gobierno municipal y de reconocer la diversidad de los municipios; es decir, existe la oportunidad de terminar con los modelos únicos o casi únicos para organizar los ayuntamientos del país. No es que antes los estados no tuvieran esta capacidad legal, lo que pasa es que no era obligatoria y por lo tanto no se ejercía. Ahora podrá verse la capacidad de los congresos estatales para romper con el centralismo.

En cuanto a tiempos para ver resultados, se esperaba que sería hasta después del 2002 cuando empezarían a apreciarse.

No hay que pasar por alto tampoco que, con o sin reforma, las propias autoridades municipales tienen tareas pendientes. Esto, en primer término, significa romper con actitudes pasivas en espera de que la federación resuelva todos sus problemas de inversión pública; es primordial, por lo tanto, que asuman la labor de incrementar sus ingresos propios; que ejerzan su facultad de cobrar el impuesto predial; que modernicen y actualicen los catastros y que influyan en las tarifas; en general, que mejoren su infraestructura administrativa para el cobro de gravámenes y, desde luego, para el ejercicio del gasto. En el actual contexto de competencia política todo ello debiera ser motivo de consideración ciudadana.

\section{La otra reforma o el Artículo 27 contra el 115}

Por si las restricciones que el Artículo 115 le impone al municipio en sus tareas de gestión del desarrollo urbano no fueran suficientes, hay que sumar aquellas que le significa el contenido del Artículo 27, que conlleva algunas contradicciones entre los núcleos ejidales -regidos por una secretaría de Estado- y las autoridades municipales.

En la relación de los artículos 115 y 27, en cuanto a los problemas urbanos y la planificación, pueden distinguirse dos etapas. Ambas tienen sus orígenes en la Constitución de 1917, en la cual quedan plasmadas las luchas políticas de las facciones más 
importantes que participaron en la Revolución Mexicana; las contradicciones que de ello derivaron, sin embargo, sólo se hacen evidentes a partir de 1976 y 1978, años en los que se publican la Ley General de Asentamientos Humanos, primero, y después el primer Plan Nacional de Desarrollo Urbano en 1978. A partir de esos años y hasta enero de 1992 correspondería la primera etapa, y la segunda correspondería a partir de febrero de 1992 hasta la actualidad. Antes de caracterizar cada fase, empero, habría que aclarar en qué consiste el conflicto.

Desde su origen, al finalizar el movimiento revolucionario iniciado en 1910, la relación entre el municipio y las instituciones agrarias han sido irreconciliables por la forma en que las demandas del movimiento agrarista se expresaron en la Constitución de 1917. Si bien el grupo agrarista no pudo introducir una jerarquía político-administrativa intermedia entre el ayuntamiento y el gobierno estatal debido a la oposición de los municipalistas, sí logró, por medio de la reforma agraria, que se formaran instancias paralelas al sistema federal. Baitenmann (2001: 105) explica cómo el Artículo 27 propició la instalación de un gran aparato burocrático bajo control del Poder Ejecutivo federal con la finalidad de normar y administrar al sector agrario; con ello, los gobiernos estatales y municipales vieron disminuida su autoridad sobre casi la mitad de su territorio.

Con la legislación agraria, el ejido se convirtió en un órgano representativo y administrativo independiente del gobierno municipal, con lo que surgieron poderes locales paralelos al ayuntamiento. Las demandas de mayor autonomía de los municipalistas no fueron atendidas como se esperaba, en tanto que el gobierno municipal sí fue abiertamente excluido del reparto agrario (Baitenmann, 2001). Lo que sí consiguió el movimiento municipalista fue que se reconociera al municipio como la base de la división territorial y de la organización política-administrativa de los estados.

Desde 1920, el ejido se transformó en una "entidad jurídica colectiva con capacidad legal, con patrimonio propio y con órganos representativos" (Rincón, 1980: 58, en Baitenmann, 2001; ver también Ibarra, 1989). Adicionalmente, nunca se reglamentó la relación ente el ejido y el municipio. Con los años, los ejidatarios se habituaron a que la autoridad era el comisariado ejidal y no el ayuntamiento; la razón aparente por la que no se corrigieron a tiempo las contradicciones entre el municipalismo y el agrarismo es que originariamente se pensó en la propiedad ejidal de 
la tierra como un paso transitorio para su posterior conversión a propiedad privada (Baitenmann, 2001: 108), lo cual nunca ocurrió. Por eso desde esos años, los gobiernos locales no tenían derecho de administrar los ejidos. ¿Cómo afectó lo anterior a las tareas de planeación urbana de los municipios?

\subsection{Primera etapa de los conflictos, 1976-1992}

Durante esos años, el marco jurídico agrario era totalmente contrario a la posibilidad de planear el crecimiento urbano; las autoridades urbanas no tenían ninguna incidencia sobre el destino de las tierras ejidales: su único recurso para influir sobre ellas era la expropiación de terrenos semiurbanizados o ya totalmente urbanizados, pero incluso tal procedimiento era controlado por la Secretaría de la Reforma Agraria (SRA). El municipio actuaba como una entidad correctora de problemas urbanos, y lo hacía de manera muy deficiente.

Tan independiente era el sector agrario de las leyes del derecho común, que no había manera de que pudiera penalizarse la venta y fraccionamiento de las tierras ejidales. Dichas penalizaciones sí estaban previstas en la Ley Agraria: consistían en el retiro de los derechos agrarios a los posesionarios de la tierra, pero dada la naturaleza corporativa del sector, siempre se protegió a sus miembros.

En suma, el Artículo 27 obró contra el municipio, sobre todo contra el Artículo 115, y más aún después de la reforma de 1983, cuando los ayuntamientos, supuestamente, quedaban facultados para ordenar el crecimiento urbano.

Por otra parte, y dada la crisis económica de los años ochenta, las agencias federales del sector urbano se retiraron ${ }^{10} \mathrm{y}$ dejaron a los municipios con las tareas de mantener por ley la elaboración de planes, pero sin relación alguna con la promoción de actividades económicas, centrados solamente en la parte físicoespacial del crecimiento, y sin ninguna presupuestación. De hecho, el único programa de suelo urbano que tuvo resultados parciales, el Sistema Nacional de Suelo para la Vivienda y el Desa-

${ }^{10}$ El cambio más importante en este sentido aconteció en 1992, cuando la Secretaría de Desarrollo Urbano y Ecología (Sedue) es sustituida por la Secretaría de Desarrollo Social (Sedesol). Este hecho marca un cambio de interés donde la planeación urbana es desplazada por políticas focalizadas de atención a la pobreza; lo urbano se retomó parcialmente en el Programa de 100 ciudades (P-100), el cual tuvo poco respaldo financiero. 
rrollo Urbano durante la gestión presidencial de Miguel de la Madrid, fue producto de la intervención directa del gobierno federal a través de la coordinación de la Secretaría de Desarrollo Urbano y Ecología (Sedue) y la SRA.

Ya para los años noventa, los programas de desarrollo urbano de ciudades importantes acumularon hasta diez años sin actualizarse, por ejemplo en el Distrito Federal, Monterrey, Cuernavaca, etc.

\subsection{Segunda etapa, 1992 hasta la actualidad: la lenta recuperación del control por parte de las autoridades municipales}

La reforma al Artículo 27, de enero de 1992, introdujo algunos cambios importantes en la relación de los sectores institucionales agrario y urbano. Las expectativas generadas, sin embargo, fueron mayores a los cambios realmente ocurridos, y ello se debe a que la reforma no fue tan radical en la medida que se mantiene independiente de los gobiernos estatales y locales al sector agrario, anclado aún a una secretaría de Estado que sigue dependiendo del jefe del Ejecutivo federal. Con todo, se espera que con el transcurrir de los años y a medida que los ejidos dejen de ser 'propiedad social', los municipios vayan retomando el control del suelo periurbano.

Los cambios más importantes fueron dos. El primero es que la tierra de 'propiedad social' deja de ser inalienable, imprescriptible e inembargable, es decir, puede venderse, rentarse e hipotecarse; lo cual en realidad consiste en reglamentar un hecho que ya sucedía desde hace mucho tiempo y en gran escala: la venta y renta de tierras. Asimismo, se busca que el núcleo ejidal deje de ser el 'dueño' de la tierra para que sean ahora los ejidatarios individuales los sujetos jurídicos propietarios; esto es, se faculta al ejidatario como 'sujeto privado' capaz de decidir el uso de su parcela y el destino de las tierras ejidales. Hay, no obstante, una contradicción que consiste en que la decisión de 'privatizar' el ejido es una decisión colectiva de la asamblea ejidal y que tiene que ser atestiguada por representantes de las instituciones agrarias, en específico, la Procuraduría Agraria.

Así, a la tradicional expropiación por causas de utilidad pública como mecanismo de conversión del suelo de propiedad social en propiedad privada, y que se ejercía en los tres tipos de 
tierras $^{11}$ que constituyen los ejidos, se agregan dos mecanismos que sólo se practica en un tipo de tierras cada uno. El primero es la adopción del dominio pleno de la superficie ejidal que, como ya se había dicho, consiste en la obtención de los certificados de propiedad individual por parte de cada ejidatario una vez que ha concluido el Procede. Este proceso únicamente se aplica a las tierras parceladas, y a partir de ello los titulares del suelo pueden comerciarlo de manera directa; sin embargo, las autoridades urbanas municipales y estatales manifiestan su preferencia para que los ejidatarios incorporen su tierra al desarrollo urbano mediante el segundo mecanismo, ante el temor de que no se desarrollen dentro de la normatividad urbanística, como de hecho ocurre.

Se ha reconocido que los procedimientos de adopción del dominio pleno sobre tierras parceladas están regulados de manera poco efectiva; se presume que en algunos casos el uso de este procedimiento ha sido inducido por terceras personas con el propósito de adquirir la tierra en condiciones ventajosas; así se continúan procesos de enajenación ilegal de tierra (véase SRA, 2000: 8).

El segundo mecanismo consiste en que los ejidatarios aporten las tierras de uso común a sociedades mercantiles inmobiliarias y que no la enajenen directamente a terceros. Pero esto nuevamente requiere la aprobación de la asamblea ejidal; consiste en la posibilidad de asociación de los miembros del núcleo agrario en lo individual o como persona moral, con los sectores público, social y privado. Esta modalidad de privatización, sin embargo, ha tenido escasa repercusión entre el sector privado y prácticamente nula en los otros dos sectores. En el primer caso, por circunstancias de muy variada índole, y en el segundo caso por falta de recursos económicos, principalmente. ${ }^{12}$

Lo anterior significa que las dos nuevas modalidades de incorporación de suelo social al desarrollo urbano ordenado han tenido resultados muy por debajo de lo esperado, y una parte de la explicación puede ubicarse en el hecho de que los ejidatarios, para iniciar al proceso, no pueden tomar decisiones en forma individual; es decir, los beneficios de la desregulación del ejido para el ejidatario son sólo aparentes.

${ }^{11}$ Los ejidos están constituidos por las tierras parceladas, que individualmente trabaja cada ejidatario, las tierras de uso común y las tierras para asentamientos humanos.

12 Para mayor detalle sobre el procedimiento de conformación de inmobiliarias ejidales y sus resultados, véase Olivera (2001: 73-74). 
El otro cambio importante introducido por la reforma al Artículo 27 es que la asamblea ejidal tiene que adaptarse a las disposiciones jurídicas locales de desarrollo urbano y a la zonificación contenida en planes y programas de desarrollo urbano para constituir zonas de urbanización ejidal y su reserva de crecimiento, así como para regularizar la tenencia de los asentamientos irregulares (Art. 39 de la Ley General de Asentamientos Humanos). Esto significa que el municipio tiene ahora la facultad de autorizar o no fraccionamientos urbanos en tierras ejidales, intervenir en la regularización de la tenencia de la tierra y conformar reservas territoriales. Sin embargo, la situación es ambigua porque aunque el municipio tiene la facultad de intervenir en ciertos procesos de gestión del suelo ejidal, quien tiene la última palabra es la asamblea ejidal, ni siquiera el ejidatario mientras no tenga su certificado ejidal.

En cierta medida, el municipio sigue al margen del ejido en forma más sutil, ya que la Ley Agraria en sus secciones tercera (artículos 56 y 62, que se refieren a la delimitación y destino de las tierras ejidales) y cuarta (artículos 63 a 72, concernientes a las tierras para asentamientos humanos) permite que las asambleas ejidales puedan determinar el destino de las tierras que no están parceladas y regularizar la zona de urbanización y la reserva de crecimiento del poblado; la única condición es que sigan las normas de Sedesol y que intervengan las autoridades municipales.

Por consiguiente, el temor de los funcionarios del ayuntamiento es que la ciudad crezca bajo normatividad en materia de planeación y desarrollo establecida por las autoridades ejidales; es decir, que el Procede regularice los proyectos ejidales y el ayuntamiento reciba asentamientos humanos no incluidos en el plan municipal (Guitrón, 1992: 50).

No obstante, el peor legado de la reforma agraria para la planeación y control del suelo urbano por parte del ayuntamiento es la falta de legalidad en la tenencia de la tierra, al reducir su capacidad para registrar propiedades, cobrar impuestos, suministrar servicios y planear el crecimiento de la ciudad, ya que según la reforma de 1992 al Artículo 27, todas las cuestiones relacionadas con la tenencia de la tierra de los ejidos y comunidades sigue siendo de jurisdicción federal (Baitenmann, 2001: 113).

Es interesante notar que en la década de los noventa, cuando algunos municipios urbanos han logrado fortalecerse, las reformas al artículo 27 ratifican el papel del aparato político, legal y 
administrativo establecido paralelamente al sistema federal en 1917; todo asunto relacionado con la sobrevivencia o el desmantelamiento del sector agrario sigue bajo el poder exclusivo y absoluto del Ejecutivo federal (Baitenmann, 2001: 119-120).

Sin embargo, como bien dice Baitenmann, entre los cambios más importantes para el municipalismo mexicano en el nuevo siglo estarán el gradual e inevitable desmantelamiento del sector ejidal y, como resultado, la nueva función que asumirá el ayuntamiento.

\section{Conclusiones: Persiste la planeación centralizada y se bifurcan las perspectivas de una gestión municipal eficaz del desarrollo urbano}

Aunado a la complejidad de las relaciones interinstitucionales entre los sectores municipal urbano y el sector agrario, hay que considerar los conflictos y desventajas que suponen las relaciones intergubernamentales entre municipio, entidades federativas y gobierno federal para propósitos de las tareas de planeación y gestión urbana. En este caso, y a pesar de que el Artículo 115 le ha conferido al municipio el carácter de nivel de gobierno, eso no implica que también sea un organismo independiente hacedor de políticas urbanas, sino que se mantiene como una entidad administradora de los servicios básicos y ejecutora de programas y políticas decididos en el ámbito federal con lineamientos uniformes y con acciones obligatorias que además están unidas al otorgamiento de fondos.

En este sentido, se establecen lineamientos de política urbana desde el Programa Nacional de Desarrollo Urbano en cada sexenio, que se pretende sean aplicables a la realidad de todos los municipios del país. Estos lineamientos tienen que ser incorporados en los programas estatales de desarrollo urbano, y finalmente, los planes municipales de desarrollo urbano deben sujetarse además a las consideraciones que introduzcan estos últimos. De este modo, la subordinación entre niveles de gobierno se mantiene vigente.

Ciertamente tiene que haber coherencia en los distintos programas, pero este procedimiento no permite que haya innovación en los planes y programas municipales. Incluso, las delegaciones estatales de la Sedesol tienen como encargo validar el contenido de los planes municipales. Asimismo, dado que los planes estatales o municipales tienen que ser publicados en el periódico oficial por 
el gobernador respectivo, no son pocas las ocasiones en que los planes municipales o de áreas conurbadas ya actualizados no pueden sustituir a los vigentes porque se retrasa deliberadamente la publicación del plan estatal, o se retrasa el de áreas conurbadas, lo que afecta en este caso a los planes municipales.

En este sentido, la planeación territorial en México constituye un entramado de relaciones complejas en las que participan los tres niveles de gobierno, pero con un esquema que garantiza tanto la subordinación del gobierno estatal al federal, como del municipal a los otros niveles de gobierno (Villar, 1999: 91). Esto constituye una paradoja más en las relaciones intergubernamentales del municipio en el área de la planificación urbana, dado que, al mismo tiempo que el gobierno federal es el canal para la obtención de recursos financieros, su proceder centralizado es un obstáculo para que los gobiernos municipales ejerzan a plenitud sus capacidades en la gestión del desarrollo urbano.

Cambiar la situación descrita tomará más tiempo del que pudo haberse pensado cuando la reforma municipal en el nivel federal se llevó a cabo. El obstáculo principal, como se ha advertido, es la larga tradición de centralismo y verticalidad en el sistema político nacional y por lo tanto en la elaboración de políticas públicas. Este elemento, incluso, tiene más peso que las deficiencias u omisiones que pudieran señalarse a las reformas municipal y agraria que se han descrito a lo largo del trabajo. La reforma municipal, de hecho, da los elementos a los congresos estatales para que adapten la reforma federal a la situación particular que se vive en cada uno de ellos, y de esa manera realizar reformas innovadoras que favorezcan el trabajo de los municipios en el largo plazo.

Sin embargo, y contrario a lo que hubiera podido esperarse en términos de que los estados ejercieran su potencial federalista, las pocas evidencias sobre las adecuaciones que las legislaturas estatales hicieron a sus constituciones en materia municipal apuntan en el sentido de una bifurcación. Mientras algunas legislaturas estatales se apegaron de manera textual a la reforma federal al Artículo 115, como en Chihuahua, Chiapas y Campeche, un grupo minoritario hizo aportaciones propias al diseño jurídico de sus municipios con diferentes grados de innovación; es el caso de Baja California, Colima, Tlaxcala, Oaxaca y Coahuila (Guillén y Ziccardi, 2004).

La importancia de que las reformas estatales sean tradicionales o innovadoras reside, de acuerdo con los autores arriba cita- 
dos, en que impactan en todos los asuntos prioritarios de la vida municipal como son la hacienda, la descentralización de funciones y servicios, la profesionalización del aparato de gobierno y el desarrollo de formas más evolucionadas de participación ciudadana, entre otros. Lo que veremos en el mediano plazo, al parecer, será la emergencia de una diversidad en la capacidad de gestión y de gobierno de los municipios del país, que prolongará por un lapso todavía mayor el logro de una gestión eficaz del desarrollo urbano. En este caso, sin embargo, es fundamental que en la parte de adecuación jurídica de las constituciones estatales se realicen innovaciones de acuerdo con la realidad que se vive en cada estado de la federación. Algo que caracteriza precisamente al país es la diversidad de los municipios que lo integran, los cuales no pueden ser tratados de manera uniforme, como se hace en la reforma federal al Artículo 115.

En suma, las reformas municipal y agraria en México establecieron las bases para un trabajo de gestión del desarrollo urbano que permite solucionar algunos problemas, pero no otros. Sin embargo, constituyen un basamento fundamental a partir del cual debe seguirse trabajando con perspectivas de largo plazo aprovechando, primero, todas las posibilidades que ofrecen; y después, mediante iniciativas locales, impulsar los cambios necesarios para seguir adelante. El trayecto, sin duda, será complejo y seguramente seguirá direcciones diversas.

\section{Bibliografía}

Aguilar, L. F. (1996), "El federalismo mexicano: funcionamiento y tareas pendientes", en A. Hernández (coord.), ¿̇Hacia un nuevo federalismo?, Fideicomiso Historia de las Américas, México, El Colegio de México, Fondo de Cultura Económica, México, pp.109-152.

Azuela, A. (1988), “Obedézcase pero no se cumpla. La reforma municipal y el régimen local de la gestión urbana", Alegatos, núm. 10, septiembre-diciembre, pp. 8-12.

(1989a),"El significado jurídico de la planeación urbana en México", en G. Garza (coord.), Una década de planeación urbano-regional en México, 1978-1988, El Colegio de México, México. 
(1989b), La ciudad, la propiedad privada y el derecho, El Colegio de México, México.

Baitenmann, H. (2001), "Las paradojas de las conquistas revolucionarias: municipio y reforma agraria en el México contemporáneo", Gestión y Política Pública, vol. x, núm. 1, primer semestre, pp. 103-123.

Cabrero, E. (2000a), "Usos y costumbres en la hechura de las políticas públicas en México. Límites de las policy sciences en contextos cultural y políticamente diferentes", Gestión y Política Pública, vol. Ix, núm. 2, pp. 5-32.

(2000b), "Primera Mesa. Facultades específicas y facultades compartidas de los tres ámbitos de gobierno", en J. Guerrero y T. Guillén (coords.), Reflexiones en torno a la reforma municipal del Artículo 115 constitucional, CIDE y Miguel Ángel Porrúa, México, pp. 33-62.

Castells, M. (1974), La cuestión urbana, Siglo xxI Editores, México.

Coraggio, J. L. (1991), Ciudades sin rumbo, Ciudad y siap, Quito.

García, R. (2000), "Segunda Mesa. La diversidad socioeconómica del conjunto municipal”, en J. Guerrero y T. Guillén (coords.), Reflexiones en torno a la reforma municipal del Artículo 115 constitucional, CIDE y Miguel Ángel Porrúa, México, pp. 63-95.

Guerrero, J. P. (2000), "Comentarios finales sobre la reforma aprobada por el Congreso Federal en junio de 1999", en J. Guerrero y T. Guillén (coords.), Reflexiones en torno a la reforma municipal del Artículo 115 constitucional, CIDE y Miguel Ángel Porrúa, México, pp. 223-233.

Guillén, T. (2000), "La reforma del 115 constitucional. El gobierno municipal, federalismo y relaciones intergubernamentales", en J. Guerrero y T. Guillén (coords.), Reflexiones en torno a la reforma municipal del Artículo 115 constitucional, cIDE y Miguel Ángel Porrúa, México, pp. 245-253. 
y A. Ziccardi (coords.) (2004), Innovación y continuidad del municipio mexicano. Análisis de la reforma municipal de 13 estados de la república, Cámara de Diputados, IIS-UNAM, Miguel Ángel Porrúa, México.

Guitrón, R. (1992), “Comentarios transcritos del taller de análisis y definición de políticas sociales: 'La crisis de la vivienda en Tijuana, Baja California'”, El Colegio de la Frontera Norte, 16 y 17 de octubre.

Hernández, A. (1996), "Las tensiones internas del federalismo mexicano", en A. Hernández (coord.), ¿Hacia un nuevo federalismo?, Fideicomiso Historia de las Américas, El Colegio de México, Fondo de Cultura Económica, México, pp. 15-33.

Hernández, D. (2000), "La oferta de suelo", Reforma agraria, reforma urbana, la plusvalía de la tierra social para ejidatarios y comuneros, Secretaría de la Reforma Agraria, Memorias, Veracruz, 6 y 7 de enero, pp. 37-38.

Ibarra, J. L. (1989), Propiedad agraria y sistema político en México, El Colegio de Sonora, Porrúa, México.

Lefevre, Ch. (1999), "Building Metropolitan Governments in Europe: 1960-2000. From Functional to Policy Legitimacy", International Forum on Metropolization, Santa Cruz, Bolivia, marzo.

Massolo, A. (1991), "Descentralización y reforma municipal: ¿fracaso anunciado y sorpresas inesperadas?", en A. Massolo, et al. (coords.), Procesos rurales y urbanos en el México actual, UAM-I, México, pp. 13-62.

Morales, C. y S. García (2004), "Elementos para una discusión en torno a la coordinación financiera y fiscal metropolitana”, en L. González (comp.), Desafío metropolitano, unAM, Asamblea Legislativa del Distrito Federal, PUEC, Coordinación de Humanidades, México, pp. 201-237.

Olivera, G. (2001), “Trayectoria de las reservas territoriales en México: irregularidad, desarrollo urbano y administra- 
ción municipal tras la reforma constitucional de 1992”, EURE, Revista Latinoamericana de Estudios Urbano Regionales, vol. XXVII, núm. 81, pp. 61-84.

Pírez, P. (2002), “Gestión metropolitana”, conferencia en Ciudad Universitaria, México, 14 de enero.

Polèse, M. (1998), Economía urbana y regional: introducción a la relación entre territorio y desarrollo, Cartago, Asociación de Editoriales Universitarias de América Latina y El Caribe, Libro Universitario Regional, Colombia.

Restrepo, D. (2001), “Dimensión espacial y política de la reestructuración capitalista", Economía, Sociedad y Territorio, vol. III, núm. 9, El Colegio Méxiquense, A.C., pp. 93126.

Rincón, R. (1980), El ejido mexicano, Centro Nacional de Investigaciones Agrarias, México.

Rodríguez, A. y E. Oviedo (2001), Gestión urbana y gobierno de áreas metropolitanas, Comisión Económica para América Latina y el Caribe (CEPAL), serie Medio Ambiente y Desarrollo 34, Santiago de Chile.

SRA (Secretaría de Reforma Agraria) (2000), Reforma agraria, reforma urbana, la plusvalía de la tierra social para ejidatarios y comuneros. Memorias, Veracruz, 6 y 7 de enero.

Smolka, M. (2001), "Introducción", Primer Seminario Internacional 'Mercados de Suelo Urbano', PUEC-UNAM y Lincoln Institute of Land Policy, Ciudad Universitaria, México, 14 de junio.

Sedesol (Secretaría de Desarrollo Social) (1999), Incorporación de suelo al desarrollo urbano, Dirección General de Desarrollo Urbano, México.

UN (United Nations, Organización de las Naciones Unidas) (1995), Metropolitan Governance. Patterns and Leadership. Report of a High-Level Interregional Meeting, abril 18-20, Quito, Ecuador, Nueva York. 
Villar, A. (1999), La impotencia municipal en el ordenamiento urbano. Herencia del centralismo y la subordinación, Plaza y Valdés-uaeméx, México.

Wario, E. (2004), "Guadalajara: medio siglo de gestión metropolitana”, en L. González (comp.), Desafío metropolitano, unAm, Asamblea Legislativa del Distrito Federal, PUEC, Coordinación de Humanidades, México, pp. 89-119.

Zepeda, M. (2000), “La plusvalía de la vivienda”, Reforma agraria, Reforma urbana, la plusvalía de la tierra social para ejidatarios y comuneros, Memorias, SRA, Veracruz, México, 6 y 7 de enero, pp. 42-45.

Enviado: 29 de enero de 2004.

Reenviado: 11 de mayo de 2004. Aceptado: 18 de noviembre de 2004.

Guillermo Olivera Lozano es investigador del Centro Regional de Investigaciones Multidisciplinarias (CRIM) de la Universidad Nacional Autónoma de México (UNAM), ubicado en Cuernavaca, Morelos. Tiene estudios de licenciatura y maestría en geografíaplaneación en la Facultad de Filosofía y Letras de la UNAM. Actualmente cursa el doctorado en urbanismo en la Facultad de Arquitectura de la misma institución. Sus líneas de investigación actuales son la reestructuración económica y su impacto territorial, así como la planeación y análisis del desarrollo urbano y regional. Entre sus publicaciones más recientes están: 1) "Los clichés detrás de las micro y pequeñas industrias: panorama internacional y de su evolución reciente en México", Investigación Económica, vol. 61, núm. 238, unAM, Facultad de Economía, México, 2001, pp. 109-156; 2) "Implicaciones económico-territoriales del auge exportador mexicano", Estudios Demográficos y Urbanos, vol. 16, núm. 47, El Colegio de México, 2001, pp. $375-413$; 3) "Trayectoria de las reservas territoriales en México: irregularidad, desarrollo urbano y administración municipal tras la reforma constitucional de 1992", Revista Latinoamericana de Estudios Urbano Regionales EURE, vol. XXVII, núm. 81, Santiago de Chile, 2001, pp. 61-84, y 4) "Desaceleración, crisis, reac- 
tivación y recesión industrial de la región centro de México. Un largo ciclo de reestructuración del núcleo y la periferia”, Revista Latinoamericana de Estudios Urbano Regionales EURE, vol. XXVII, núm. 82, Santiago de Chile, 2001, pp. 65-100, con Julio Guadarrama. 